\title{
Non-Hodgkin's Lymphomas Involving the Uterus: A Clinicopathologic Analysis of 26 Cases
}

\author{
Russell Vang, M.D., L. Jeffrey Medeiros, M.D., Chul S. Ha, M.D., Michael Deavers, M.D. \\ Department of Pathology, The University of Texas-Houston Medical School (RV), and the Departments of \\ Pathology (LJM, MD) and Radiation Oncology (CSH), The University of Texas-M.D. Anderson Cancer \\ Center, Houston, Texas
}

Non-Hodgkin's lymphomas (NHL) involving the uterus may be either low-stage neoplasms that probably arise in the uterus (primary) or systemic neoplasms with secondary involvement. In this study, 26 NHL involving the uterus are reported. Ten cases were stage $I_{E}$ or $I_{E}$ and are presumed to be primary. The mean age of patients at presentation was 55 years (range, 35 to 67 years), and abnormal uterine bleeding was the most frequent complaint (six patients). Nine of 10 tumors involved the cervix. Histologically, eight were diffuse large B-cell lymphoma (DLBCL); one was follicle center lymphoma, follicular, grade 1; and one was marginal zone B-cell lymphoma. At 5 years of clinical followup, five of six patients were alive after treatment. In 12 cases, uterine involvement was part of a systemic disease at diagnosis, either stage $\mathrm{III}_{E}$ or IV. The mean patient age at the time that uterine involvement was detected was 58 years (range, 22 to 75 years); 6 of 12 had abnormal uterine bleeding. Six tumors involved both cervix and corpus, four corpus, and two cervix. Six were DLBCL; two were small lymphocytic lymphoma; three were follicle center lymphoma, follicular, grade 1 (two cases) or grade 2 (one case); and one was precursor T-cell lymphoblastic lymphoma. At 5 years of clinical follow-up, two of seven patients were alive after treatment. Four DLBCL arose in patients with incomplete clinical information; therefore, stage is unknown. We conclude that low-stage (presumably primary) uterine NHL are most commonly DLBCL, predominantly arise in the cervix, and cause abnormal uterine bleeding. High-stage NHL are a heterogeneous group of B-cell neoplasms that can involve the cervix or the corpus.

Copyright () 2000 by The United States and Canadian Academy of Pathology, Inc.

VOL. 13, NO. 1, P. 19, 2000 Printed in the U.S.A.

Date of acceptance: July 19, 1999.

Address reprint requests to: Michael Deavers, M.D., The University of Texas-M.D. Anderson Cancer Center, Department of Pathology Box 85, 1515 Holcombe Boulevard, Houston, TX 77030-4095.
KEY WORDS: B-cell, Immunohistochemistry, NonHodgkin's lymphoma, Uterus.

Mod Pathol 2000;13(1):19-28

Non-Hodgkin's lymphoma (NHL) can involve extranodal sites. Common extranodal locations include the gastrointestinal tract and skin; however, the female reproductive system also may be affected, most commonly the ovary. Infrequently, NHL may involve the uterus. Numerous studies of NHL involving the uterus have been reported in the literature, and we have identified at least 15 case series that describe three or more patients (1-16). However, in most of these studies, clinical follow-up is short and no comparisons are made between cervix and corpus involvement or between primary and secondary neoplasms. Furthermore, many studies were reported before the advent of immunohistochemical analysis.

In this study, we describe 26 cases of NHL involving the uterus, most of which were treated within the same institution, thus representing the experience at a tertiary care center. We further compare the clinicopathologic differences between primary and secondary NHL and report the results of immunohistochemical studies.

\section{MATERIALS AND METHODS}

Twenty-six cases of NHL involving the uterus were collected from the files at M.D. Anderson Cancer Center (MDACC) between 1981 and 1998. Of this group, the initial biopsy or surgery in 19 patients was done at another institution, but the histologic slides were reviewed at MDACC; 11 of these patients were treated at MDACC. In seven additional patients, initial biopsy or surgery and treatment were done at MDACC.

Patients were staged according to the Harris and Scully modification (4) of the Ann Arbor staging system for extranodal lymphomas. Stage was assessed at the time of the initial diagnosis of uterine involvement. Low-stage (presumably primary) neo- 
plasms were defined as being either Stage $\mathrm{I}_{\mathrm{E}}$ or $\mathrm{II}_{\mathrm{E}}$. High-stage (presumably secondary) neoplasms were Stage $\mathrm{III}_{\mathrm{E}}$ or IV. Stage was considered uncertain if insufficient clinical information was available.

The distribution of the neoplasms was further categorized according to the region of involvement as cervix, corpus, or cervix + corpus. Designation of cervix or corpus was based on the predominant site of NHL in the uterus, determined by either pathologic data or pathologic and clinical information. The classification of cervix + corpus indicated that both regions had significant involvement. A subset of patients in all three groups had additional nonuterine sites of involvement (e.g., lymph nodes).

Clinical follow-up was available for 21 patients, obtained by review of the medical record. Four patients were lost to follow-up.

All NHL were histologically classified according to the revised European-American classification of lymphoid neoplasms. The immunophenotype was determined by immunohistochemical methods using either frozen or fixed, paraffin-embedded tissue sections. For the paraffin section studies, the following antibodies were used: LCA (CD45; 1:300), L26 (CD20; 1:700), anti-BCL-2 (clone 124; 1:10), and anti-CD3 (1:150) (DAKO, Carpinteria, CA); Leu22 (CD43; 1:120) (Becton-Dickinson, San Jose, CA); and UCHL-1 (CD45RO; 1: 100). For the frozen section studies, a number of B-cell and T-cell antibodies were variably used, including those specific for CD3, CD4, CD5, CD8, CD10, CD19, CD20, CD22, and immunoglobulin heavy and light chains. The immunohistochemical results were based on analysis of uterine specimens in 18 cases and on nonuterine tissues involved by the NHL in 8 cases. Flow cytometry was used in one case. Gene rearrangement studies were done by Southern blot analysis of DNA extracted from frozen tissue in three cases and by a polymerase chain reaction method using DNA extracted from paraffin-embedded tissue in one case.

\section{RESULTS}

\section{Low-Stage Uterine NHL \\ Clinicopathologic features}

Ten neoplasms were low stage; 7 Stage $\mathrm{I}_{\mathrm{E}}$ and 3 Stage $\mathrm{II}_{\mathrm{E}}$. Patients ranged in age from 35 to 67 years (mean, 55 years). The most common presentation was abnormal uterine bleeding (six patients [60\%]). The other patients presented with a pelvic mass, or the NHL was an incidental finding. The pelvic examination revealed cervical mass (two patients), cervicovaginal mass (two patients), mass adjacent to cervix (one patient), adnexal mass (mature cystic teratoma) with bulky cervix (one patient), cervical polyp (one patient), endometrial polyp (on patient), and no documented abnormalities (one patient). The pelvic examination findings were unknown in one patient. Nine of 10 NHL predominantly involved the cervix (Table 1).

The diagnosis of NHL was established by cervical biopsy, curettage, conization, endometrial biopsy, or hysterectomy. The patients were treated by chemotherapy and radiation therapy (five patients) or chemotherapy alone (two patients). One patient who was treated by chemotherapy and radiation therapy also had total abdominal hysterectomy-bilateral salpingooophorectomy. Two patients were treated only by hysterectomy. One recent case has not been treated.

Clinical follow-up ranged from 7 months to 10 years (mean, 5.1 years) and was available for 7 of 10 patients. Five patients (Cases 3, 5-7, and 10) were alive without disease at last follow-up. One patient (Case 8) had relapse and multiple recurrences of lymphoma with progression and death 1 year later (cause of death unknown). Another patient (Case 9) achieved complete clinical remission but died of unknown cause 9 years later. Although follow-up was relatively short (7 months) for one patient (Case 2), a complete clinical response was achieved. Case 4 is recently diagnosed. At 5 years of follow-up for six patients, five (83\%) were alive.

TABLE 1. Primary Non-Hodgkin's Lymphoma Involving the Uterus

\begin{tabular}{|c|c|c|c|c|c|c|c|}
\hline $\begin{array}{c}\text { Case } \\
\text { No. }\end{array}$ & $\begin{array}{l}\text { Age } \\
(\mathrm{yr})\end{array}$ & Presentation & Stage $/^{a}$ & Site & Diagnosis & Treatment & Follow-up \\
\hline 1 & 35 & AUB & $\mathrm{I}_{\mathrm{E}}$ & Corpus & DLBCL & TAH & N/A \\
\hline 2 & 39 & Vaginal mass & $\mathrm{I}_{\mathrm{E}}$ & Cervix & DLBCL & CT, RT & A, $7 \mathrm{mo}$ \\
\hline 3 & 46 & Adnexal mass and pain & $\mathrm{I}_{\mathrm{E}}$ & Cervix & DLBCL & TAH-BSO & A, $4.5 \mathrm{yr}$ \\
\hline 4 & 53 & Cervical dysplasia & $\mathrm{I}_{\mathrm{E}}$ & Cervix & MZBCL & Cervical conization & Recent case \\
\hline 5 & 57 & AUB & $\mathrm{II}_{\mathrm{E}}$ & Cervix & DLBCL & CT, RT & NED, $10 \mathrm{yr}$ \\
\hline 6 & 57 & AUB & $\mathrm{II}_{\mathrm{E}}$ & Cervix & DLBCL & CT, RT & NED, 5 yr \\
\hline 7 & 61 & AUB & $\mathrm{II}_{\mathrm{E}}$ & Cervix & FCL-F, grade 1 & TAH-BSO, CT, RT & NED, 6 yr \\
\hline 8 & 65 & AUB & $\mathrm{I}_{\mathrm{E}}$ & Cervix & DLBCL & CT & $\mathrm{D}, 1 \mathrm{yr}$ \\
\hline 9 & 67 & Cervical mass & $\mathrm{I}_{\mathrm{E}}$ & Cervix & DLBCL & Cervical conization, CT & $\mathrm{D}, 9 \mathrm{yr}$ \\
\hline 10 & 67 & AUB & $\mathrm{I}_{\mathrm{E}}$ & Cervix & DLBCL & $\begin{array}{l}\text { Cervical conization, } \\
\text { CT, RT }\end{array}$ & NED, 5 yr \\
\hline
\end{tabular}

AUB, abnormal uterine bleeding; DLBCL, diffuse large B-cell lymphoma; MZBCL, marginal zone B-cell lymphoma; FCL-F, follicle center lymphoma, follicular; TAH, total abdominal hysterectomy; CT, chemotherapy; RT, radiation therapy; BSO, bilateral salpingo-oophorectomy; A, alive; NED, no evidence of disease; D, dead.

${ }^{a}$ Modified Ann Arbor stage (4). 


\section{Histologic and immunophenotypic features}

The histologic types of NHL were diffuse large B-cell lymphoma (DLBCL; eight patients); follicle center lymphoma, follicular, grade 1 (one patient); and marginal zone B-cell lymphoma MZBCL (one patient). The DLBCL were composed of sheets of large neoplastic cells that infiltrated deeply through cervical stroma, frequently with interspersed residual collagen bundles. Thick and densely hyalinized bundles of collagen were conspicuous in some cases. When the lower uterine segment was involved, preserved bundles of smooth muscle were pushed apart by sheets of lymphoma. In some cases, the DLBCL were vaguely nodular, as neoplastic cells were compartmentalized by collagen bands. Endocervical glands were also surrounded and separated by sheets of lymphoma (Fig. 1) and frequently were dilated and filled with mucin. When the overlying surface epithelium was not eroded, the neoplastic cells did not infiltrate epithelium to form lymphoepithelial lesions (Fig. 2). Often, collagenous stroma separated the DLBCL from the ectocervical epithelium.

Cytologically (Fig. 3), the neoplastic cells were moderate to large cells that usually were round but sometimes were elongated. Eosinophilic cytoplasm was moderate but was often retracted by fixation

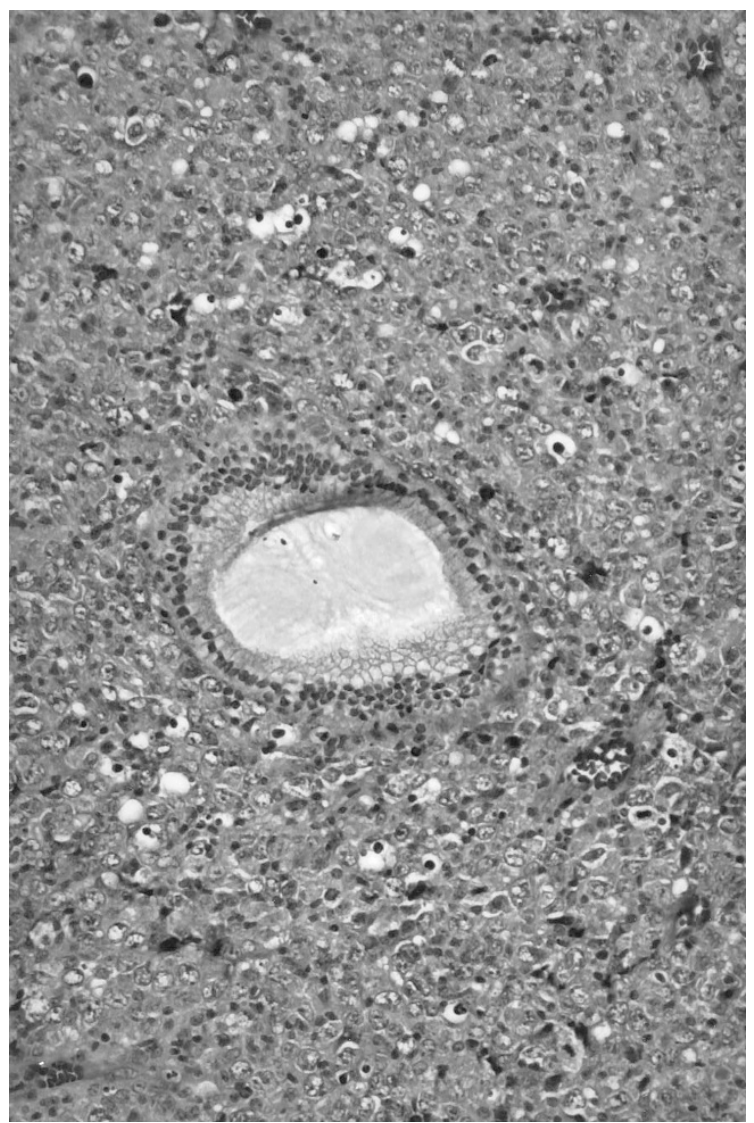

FIGURE 1. Primary diffuse large B-cell lymphoma surrounding endocervical glands $(200 \times)$.

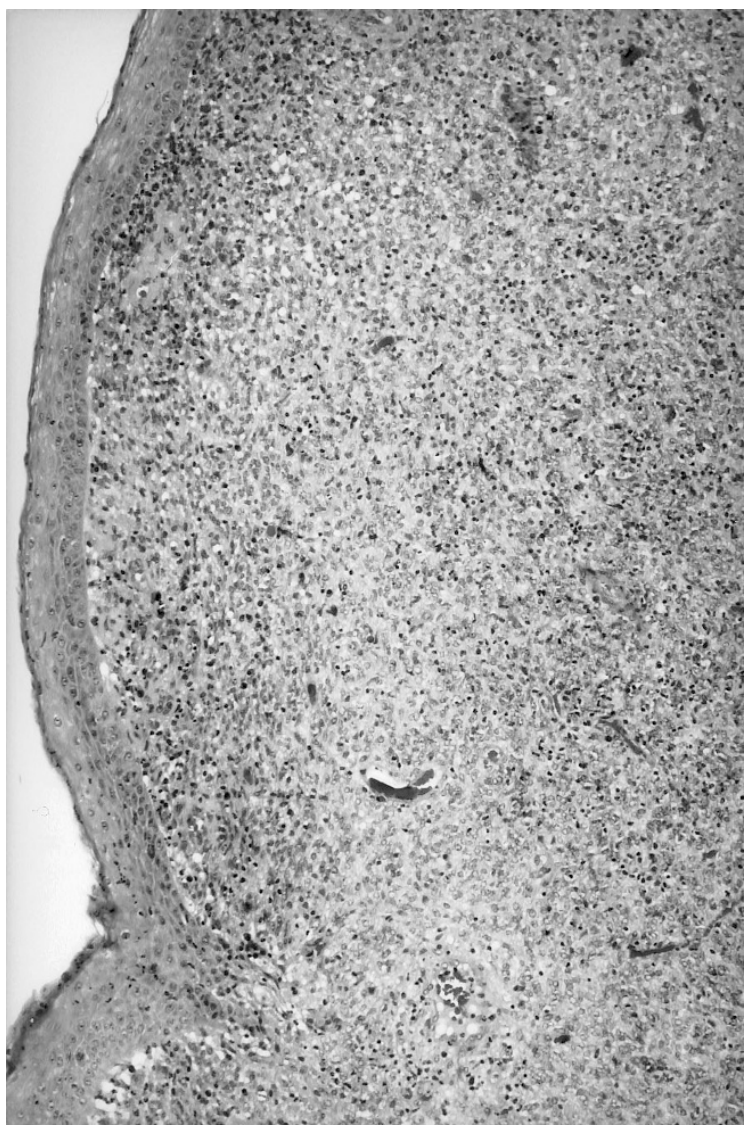

FIGURE 2. Primary diffuse large B-cell lymphoma with sparing of the squamous epithelium (100×).

artifact. The nuclei were slightly pleomorphic and multilobated in some cases. The chromatin was vesicular, and small nucleoli were seen. Mitoses were conspicuous. One case, without corpus involvement, had associated microglandular hyperplasia in the lower uterine segment.

The follicle center lymphoma, follicular, grade 1 had a follicular pattern of relatively monomorphous large follicles that coalesced and deeply infiltrated cervical stroma, abutted the overlying squamous epithelium, and were closely spaced. The follicles were devoid of mantle zones, tingible-body macrophages, and mitoses. Minor diffuse areas were present. The follicles were composed predominantly of small cleaved cells, with occasional large noncleaved cells.

The MZBCL (Fig. 4) was composed of expansile sheets that diffusely infiltrated cervical stroma. The lymphoma tended to spare the overlying squamous cervical epithelium, but there were areas of epithelial infiltration. The lesion was composed predominantly of small, round to slightly irregular lymphoid cells. A minor population of larger and atypical lymphoid cells were individually scattered throughout the neoplasm. Reactive follicles were also present, surrounded by neoplasm.

Immunohistochemical data were available in all 10 cases, which were B-cell neoplasms. Eight cases 


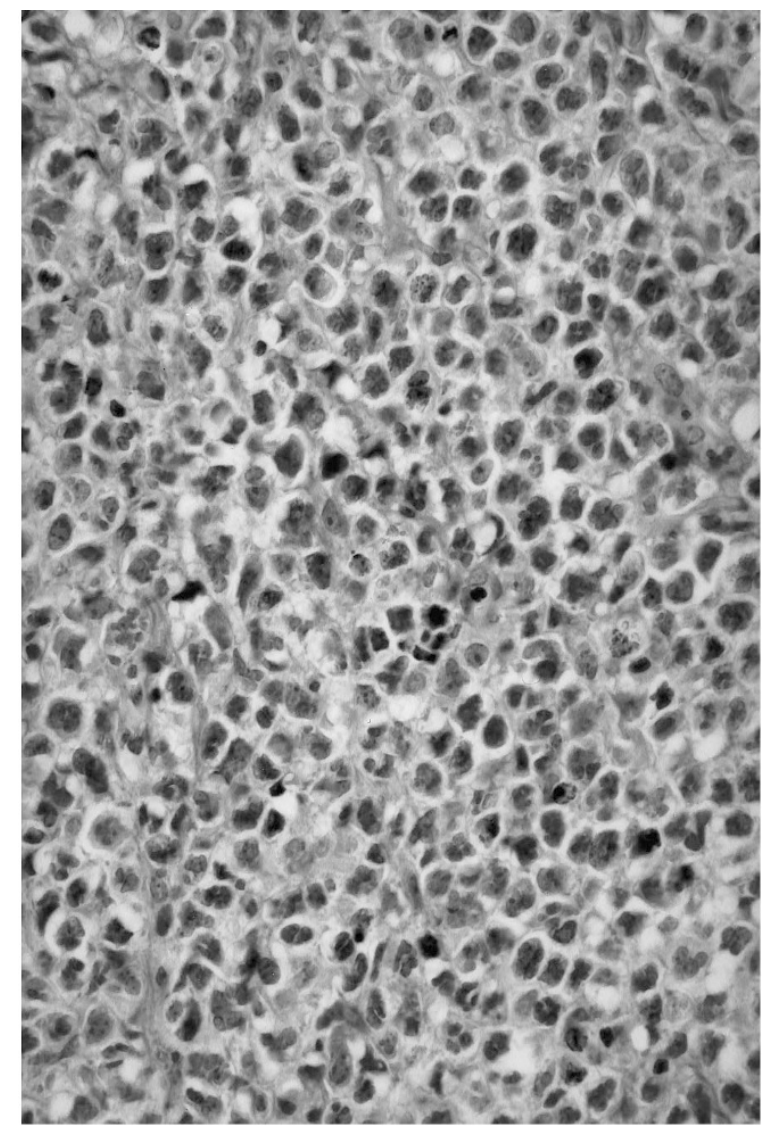

FIGURE 3. Primary diffuse large B-cell lymphoma. Tumor cell cytoplasm is retracted due to fixation artifact $(400 \times)$.

studied using formalin-fixed tissue were CD20 positive (Fig. 5), and seven cases tested were negative for CD3 and/or CD43. One of two cases analyzed expressed monotypic immunoglobulin lambda light chain. Three cases studied using frozen tissue were positive for pan-B-cell antigens and negative for T-cell antigens, one of which expressed monotypic immunoglobulin lambda light chain.

Molecular studies were done on three cases. Two neoplasms were assessed using Southern blot analysis and a genomic probe derived from the joining region of the immunoglobulin heavy chain gene (JH). The MZBCL case was analyzed using a polymerase chain reaction method. All three neoplasms had monoclonal immunoglobulin heavy chain gene rearrangements.

\section{High-Stage Uterine NHL}

\section{Clinicopathologic features}

Twelve cases were high stage at the time of diagnosis (Stage $\mathrm{III}_{\mathrm{E}}$ or IV). Patients ranged in age from 22 to 75 years (mean, 58 years). The most common presenting feature was abnormal uterine bleeding (six patients). Other presenting features included pelvic mass (two patients), abdominal distension and pain (one patient), lung infiltrates (one pa- tient), uterine prolapse with cystocele and rectocele (one patient), weight loss with anemia and axillary lymphadenopathy (one patient), urinary frequency and rectal urgency (one patient), and gluteal lesions with a leg nodule (one patient). The pelvic examination results, known for nine patients, revealed an enlarged uterus (four patients), cervical mass (one patient), erythematous cervical lesions (one patient), pelvic mass with indurated cervix (one patient), and no abnormalities (two patients). The region of uterine involvement was cervix + corpus (six patients), corpus (four patients), and cervix (two patients) (Table 2).

Five patients had hysterectomy, four had endometrial biopsy or uterine curettage, two had cervical biopsy, and one had myomectomy. The patients were treated using chemotherapy and radiation therapy (six patients), chemotherapy alone (five patients), and total abdominal hysterectomy-bilateral salpingooophorectomy (one patient). Three of the patients who received chemotherapy and radiation therapy also underwent myomectomy, total abdominal hysterectomy-bilateral salpingo-oophorectomy, or bone marrow transplantation. Two patients who received chemotherapy alone also underwent hysterectomy. Clinical follow-up, after the diagnosis of uterine involvement by NHL, was available for all 12 patients and ranged from 2 months to 6 years (mean, 2.2 years). At 5 years, two of seven patients were alive after therapy. Additional features during the course of the disease included remission and relapse (Cases 11 and 18), remission with relapse and eventual death (Case 12), recurrence with progression (Case 14), persistent and progressive disease (Case 19), partial response but stable disease (Case 20), and recurrence of small lymphocytic lymphoma with eventual transformation to large cell lymphoma (Richter's syndrome; Case 22). Clinical information on the course of disease for the other patients was not available.

\section{Histologic and immunophenotypic features}

The histologic types of NHL were DLBCL (six patients) (Fig. 6); small lymphocytic lymphoma (two patients); follicle center lymphoma, follicular, grade 1 (two patients) and grade 2 (one patient); and precursor T-cell lymphoblastic lymphoma (one patient).

Immunohistochemical data were available in all 12 cases. Using formalin-fixed tissue for seven B-cell neoplasms, the neoplastic cells were positive for CD20 (six of six cases), monotypic immunoglobulin lambda light chain (one case assessed), BCL-2 (two cases assessed), and CD43 (three cases analyzed). Four cases studied were negative for CD3. Using frozen tissue on four cases, the neoplastic cells were positive for CD20 (two of two cases), CD22 (two of two cases), CD10 (one case assessed), CD5 (one case analyzed), and monotypic immuno- 

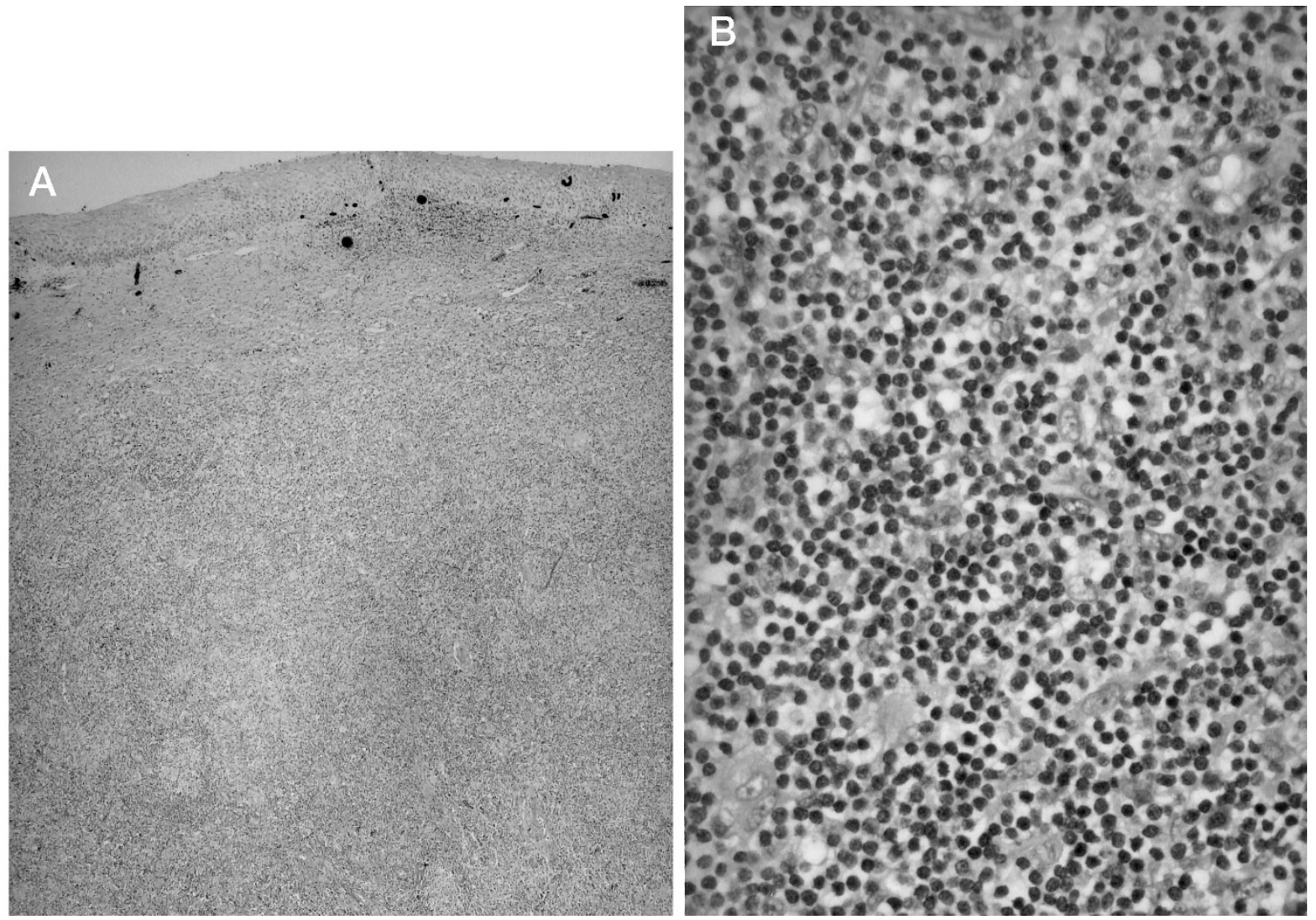

FIGURE 4. Primary marginal zone B-cell lymphoma at $40 \times($ A) and $400 \times(B)$.

globulin lambda light chain (one case studied). Three cases studied were negative for CD3. Using fresh tissue, one neoplasm (also immunohistochemically assessed using formalin-fixed tissue) was studied by flow cytometry and was positive for monotypic immunoglobulin lambda light chain, CD10, CD19, and CD20. The one T-cell neoplasm, assessed using formalin-fixed tissue, was positive for TdT, CD3, and CD5 and negative for immunoglobulin light chains and B-cell antigens.

Molecular studies were done on one B-cell neoplasm using Southern blot analysis and a genomic $\mathrm{JH}$ probe. Monoclonal immunoglobulin heavy chain gene rearrangements were identified.

\section{Uncertain Stage}

\section{Clinicopathologic features}

Four cases were of uncertain stage. Age was known for three of four patients, with a mean age of 43 years (range, 29 to 52 years). Clinical findings at presentation were available for two patients: abnormal uterine bleeding and pelvic pain in one and abnormal uterine bleeding with lower abdominal pain and weight loss in the other. Information regarding the pelvic examination was available for one patient who had a cervical mass. Two patients had a hysterectomy, one had an endometrial curettage, and one had a cervical biopsy (Table 3).

Information regarding therapy was incomplete; a hysterectomy was performed for two patients, and one was treated with chemotherapy and radiation therapy. Clinical follow-up was available for one patient who was alive at 1 year.

\section{Histologic and immunophenotypic features}

The histologic type of NHL was DLBCL in all four patients. Immunohistochemical data obtained using formalin-fixed tissue sections were available for all four neoplasms, which were of B-cell lineage, positive for CD20, and negative for either CD3 or CD45RO.

\section{DISCUSSION}

Uterine involvement by NHL is uncommon. In autopsy studies of patients with NHL, disease in the uterus was found in approximately $0.5 \%$ (17-19). The uterus is affected more commonly by chronic lymphocytic leukemia: 7.1 to $14.0 \%$ of patients have had uterine involvement $(18,20)$. Because of its infrequent nature, NHL involving the uterus may present diagnostic difficulties for pathologists who 


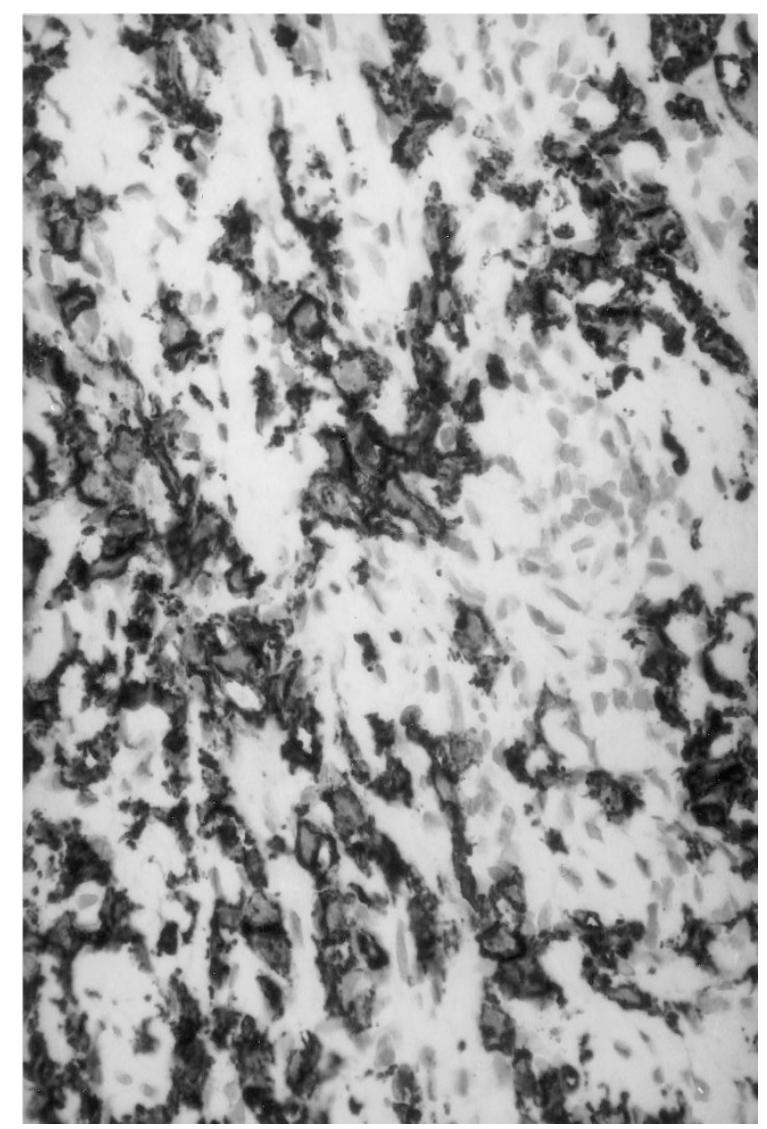

FIGURE 5. Primary diffuse large B-cell lymphoma. The neoplastic cells are B-cells positive for CD20 (immunoperoxidase with hematoxylin counterstain, $400 \times)$.

are unfamiliar with the clinicopathologic characteristics of the disease in this location.

In general, extranodal lymphomas in the literature are commonly subdivided as "primary" and "secondary." We also have chosen to use these designations in the current study, although they can become ambiguous and arbitrary. For example, a case of Stage IV uterine NHL may have the majority of the disease in the uterus. Although we have considered neoplasms such as this example to be secondary, we cannot entirely exclude primary uterine origin.

In the low-stage, presumably primary cases in this study, the mean age at presentation was 55 years, and the most frequent presentation was abnormal uterine bleeding. The majority were DLBCL. The 5 -year survival rate was $83 \%$. These findings are similar to those reported in the literature $(1,4,7,11$, $13,15,16)$. In our literature review of 15 case series (case reports were excluded) (Table 4), the following trends for low-stage tumors were recognized. The most common presentation is abnormal uterine or vaginal bleeding, the predominant site of neoplasm is usually the cervix, and the most common histologic type is diffuse large cell lymphoma. The 5-year survival rate is reported to range from 0 to $100 \%$, but the majority of series report survival in the range of 67 to $100 \%$.

One of our primary cases was a MZBCL, also known as low-grade B-cell lymphoma of mucosaassociated lymphoid tissue. These lymphomas most commonly occur in the stomach, lung, salivary glands, and thyroid gland, but virtually all extranodal sites can potentially be involved. Although the cervix is a distinctly unusual location, at least one case of MZBCL has been reported previously in this site (21).

The high-stage, presumably secondary cases in this study had the following features: the mean age at presentation was 58 years, the most frequent presentation was abnormal uterine bleeding, and the most common site of involvement was the uterine corpus ( $83 \%$ of patients). The most common histologic type was DLBCL. The 5-year survival rate was $29 \%$. The results are also similar to those in the literature (Table 4) $(5,8,9,12,14,15)$. Most highstage uterine NHL involve the corpus, the most

TABLE 2. Secondary Non-Hodgkin's Lymphoma Involving the Uterus

\begin{tabular}{|c|c|c|c|c|c|c|c|}
\hline $\begin{array}{c}\text { Case } \\
\text { No. }\end{array}$ & $\begin{array}{l}\text { Age } \\
(\mathrm{yr})\end{array}$ & Presentation & Stage $/^{a}$ & Site & Diagnosis & Treatment & Follow-up \\
\hline 11 & 22 & AUB, abdominal distension & IV & Corpus + cervix & DLBCL & CT, RT & DOD, $13 \mathrm{mo}$ \\
\hline 12 & 34 & AUB & $\mathrm{III}_{\mathrm{E}}$ & Corpus & T-LBL & CT, RT, BMT & D-NED, $10 \mathrm{mo}$ \\
\hline 13 & 52 & AUB, lung infiltrates & IV & Corpus & DLBCL & TAH-BSO & $\mathrm{A}, 2 \mathrm{mo}$ \\
\hline 14 & 56 & AUB & IV & Corpus + cervix & FCL-F, grade 1 & TAH-BSO, CT, RT & DOD, 6 yr \\
\hline 15 & 58 & Uterine prolapse, cystocele, rectocele & IV & Corpus + cervix & FCL-F, grade 1 & $\mathrm{H}, \mathrm{CT}$ & A, 2 yr \\
\hline 16 & 60 & Pelvic mass (incidental) & IV & Corpus + cervix & DLBCL & TAH-BSO, CT, RT & DOD 1 yr \\
\hline 17 & 65 & AUB & IV & Cervix & FCL-F, grade 2 & CT & A, $3 \mathrm{mo}$ \\
\hline 18 & 66 & Pelvic mass (incidental) & IV & Corpus + cervix & DLBCL & TAH-BSO, CT & A, $3 \mathrm{yr}$ \\
\hline 19 & 69 & Weight loss, anemia, axillary lymph nodes & IV & Cervix & B-SLL & CT & $\mathrm{D}, 5.5 \mathrm{yr}$ \\
\hline 20 & 69 & Urinary frequency, rectal urgency & IV & Corpus & DLBCL & M, CT RT & A, 6 mo \\
\hline 21 & 73 & Gluteal + leg nodule, AUB & IV & Corpus + cervix & DLBCL & CT & $\mathrm{D}, 4 \mathrm{mo}$ \\
\hline 22 & 75 & AUB, history of CLL & IV & Corpus & B-SLL & CT, RT & $\mathrm{D}, 5 \mathrm{yr}$ \\
\hline
\end{tabular}

AUB, abnormal uterine bleeding; CLL, chronic lymphocytic leukemia; DLBCL, diffuse large B-cell lymphoma; T-LBL, precursor T-cell lymphoblastic lymphoma; FCL-F, follicle center lymphoma, follicular; B-SLL, small lymphocytic lymphoma; CT, chemotherapy; RT, radiation therapy; BMT, bone marrow transplant; TAH-BSO, total abdominal hysterectomy-bilateral salpingo-oophorectomy; H, hysterectomy; M, myomectomy; DOD, dead of disease; D, dead; NED, no evidence of disease; A, alive.

${ }^{a}$ Modified Ann Arbor stage (4). 


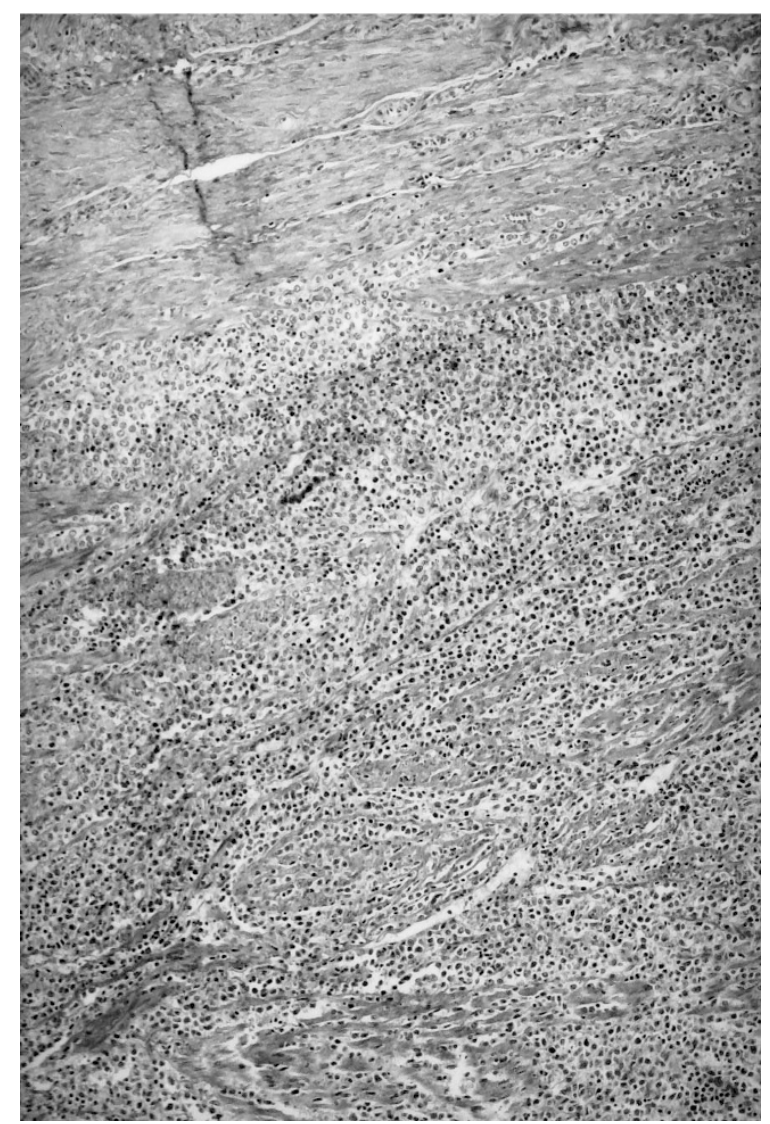

FIGURE 6. Secondary diffuse large B-cell lymphoma with myometrial invasion $(100 \times)$.

common histologic type is diffuse large cell lymphoma, and the 5-year survival rate is reported to range from 0 to $50 \%$. The more common presentation has been abnormal uterine or vaginal bleeding, but a significant proportion of patients also have presented with an ovarian mass, with secondary involvement of the uterus found at time of pathologic examination.

Pelvic symptoms or signs were at least partly responsible for the initial clinical work-up that led to the pathologic diagnosis of uterine NHL in 22 of $26(85 \%)$ of the patients in this study. The most common finding was abnormal uterine bleeding. Low-stage cases are more likely to present only with gynecologic complaints. Although a significant portion of high-stage cases also had gynecologic complaints, these patients presented with simultaneous nongynecologic manifestations that may overshadow the gynecologic findings.

In this study, unlike in many studies previously reported in the literature, immunohistochemical studies were done on every case. Uterine NHL as a group are most commonly of B-cell lineage, and all low-stage NHL were of B-cell lineage in this study. The one case of precursor T-cell lymphoblastic lymphoma in this study was generalized with many other sites of disease and leukemic involvement. Previous studies done on a limited number of cases also have shown that most uterine NHL are of B-cell lineage $(1,4,9-13,15)$.

The differential diagnosis for uterine NHL includes inflammatory conditions, other hematopoietic lesions, carcinoma, malignant mixed mullerian tumor (MMMT), endometrial stromal tumors including endometrial stromal sarcoma (ESS), melanoma, and extraosseous Ewing's sarcoma (ES)/ primitive neuroectodermal tumor (PNET).

Chronic cervicitis, papillary endocervicitis, or follicular cervicitis may be confused with low-grade follicular NHL in a limited biopsy specimen. Reactive inflammatory processes commonly have a polymorphous population of plasma cells, histiocytes, and lymphocytes without atypia. If follicles are present, the follicles are widely spaced and have well-formed mantle zones (22). The architecture of reactive lesions is usually superficial and band-like without infiltration. In distinguishing follicular hyperplasia from follicular NHL, the use of BCL-2 immunostaining may be helpful, as BCL-2 is negative in the germinal centers of reactive lymphoid follicles.

A hematologic malignancy that must be included in the differential diagnosis is extramedullary myeloid cell tumor (EMCT), also known as granulocytic sarcoma and chloroma $(23,24)$. Well- to moderately differentiated neoplasms have granulocytic or eosinophilic myelocytes and can be recognized histologically. However, poorly differentiated EMCT can closely mimic malignant lymphoma and must be studied immunohistochemically. EMCT are usually positive for myeloperoxidase, lysozyme, CD43, and CD68 and lack lymphoid markers $(23,24)$.

Langerhans' cell granulomatosis (or histiocytosis) is another hematologic lesion that must be consid-

TABLE 3. Non-Hodgkin's Lymphoma Involving Uterus of Uncertain Stage

\begin{tabular}{|c|c|c|c|c|c|c|c|}
\hline $\begin{array}{l}\text { Case } \\
\text { No. }\end{array}$ & $\begin{array}{l}\text { Age } \\
\text { (yr) }\end{array}$ & Presentation & Stage $^{a}$ & Site & Diagnosis & Treatment & Follow-up \\
\hline 23 & 29 & AUB, pelvic pain & $\mathrm{N} / \mathrm{A}$ & Corpus & DLBCL & N/A & N/A \\
\hline 24 & 49 & N/A & N/A & Cervix & DLBCL & $\mathrm{H}$ & N/A \\
\hline 25 & 52 & AUB, abdominal pain, weight loss & N/A & Cervix & DLBCL & CT, RT & A, 1 yr \\
\hline 26 & N/A & N/A & N/A & Uterus & DLBCL & $\mathrm{H}$ & N/A \\
\hline
\end{tabular}

AUB, abnormal uterine bleeding; N/A, not available; DLBCL, diffuse large B-cell lymphoma; H, hysterectomy; CT, chemotherapy; RT, radiation therapy; A, alive.

${ }^{a}$ Modified Ann Arbor stage (4). 


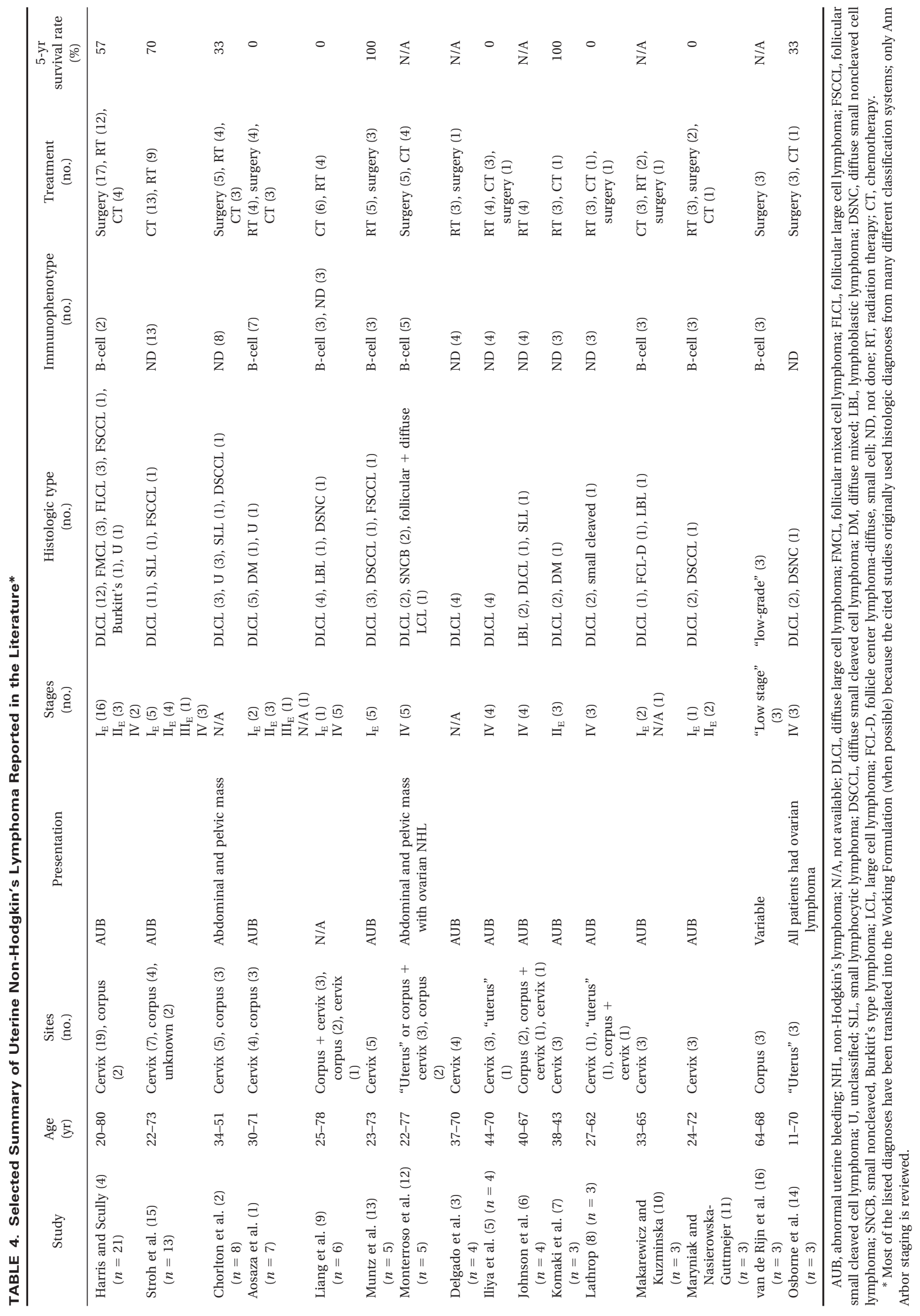


ered (25). These lesions have a component of reactive eosinophils as well as a second component of large mononuclear cells with lobulated, cleaved, or grooved nuclei. Langerhans' cells express S-100, CDla, and CD68 and are negative for lymphoid markers. Electron microscopy reveals Birbeck granules.

Epithelial tumors such as poorly differentiated, small cell neuroendocrine, and lymphoepitheliomalike carcinomas also may present diagnostic difficulty. Cohesive nests, islands, cords, glands, or association with an in situ component may be clues to the epithelial nature. Sclerosis that compartmentalizes DLBCL cells can mimic cohesive clusters or cords and must not be confused with carcinoma.

Undifferentiated carcinoma or sarcomatous small round-cell components of MMMT also should be considered when the neoplasm has a high-grade appearance (26). In addition to separate areas with obvious epithelial differentiation in an MMMT, the sarcomatous nature may be inferred if fascicular, storiform, herringbone, or heterologous tissue components are recognized. In selected cases, immunohistochemical studies using epithelial, mesenchymal, and lymphoid markers assist in distinguishing the neoplasms.

Endometrial stromal tumors including ESS may be considered when encountering a diffuse sheet of small, round, blue cells. In addition, any entrapped glands by lymphoma could cause confusion with the glandular/sex-cord variant of ESS (27). NHL should lack spindling, focal starburst hyaline structures, or the vascular pattern of endometrial stromal tumors. This vascular pattern includes regularly spaced small arterioles surrounded by slightly spindled cells that whorl around them. Endometrial stromal tumors lack lymphoid markers.

The small cell variant of melanoma also should be excluded. Alveolar architecture and classic melanoma nuclei with macronucleoli are obviously helpful but may be absent. Lack of pigmentation is not reliable for distinguishing melanoma from NHL, as melanoma can lack pigment. Melanomas express S-100 and HMB-45 and lack lymphoid markers.

ES/PNET can have a diffuse sheet-like growth pattern. However, the neoplastic cells usually will not be as large and pleomorphic as can be seen in some examples of DLBCL. Rosettes can be part of the histology of ES/PNET. ES/PNET does not express most lymphoid markers, although these tumors are positive for CD99, which can be expressed by lymphoblastic lymphoma. Also, reverse transcriptase polymerase chain reaction analysis can detect the EWS/FLI-1 fusion product characteristic of ES/PNET (28).

In conclusion, uterine NHL are usually of B-cell lineage, and the majority are DLBCL. Most uterine
NHL cause abnormal uterine bleeding. Low-stage cases most commonly involve the cervix, and affected patients have a good 5-year survival rate (83\% in this study). High-stage cases involve either the corpus or the cervix, and patients have a poorer 5 -year survival rate (29\% in this study). NHL must be kept in mind in the work-up of histologically difficult uterine neoplasms to avoid misdiagnosis.

\section{REFERENCES}

1. Aozasa K, Saeki K, Ohsawa M, Horiuchi K, Mishima K, Tsujimoto M. Malignant lymphoma of the uterus: report of seven cases with immunohistochemical study. Cancer 1993; 72:1959-64.

2. Chorlton I, Karnei RF Jr, King FM, Norris HJ. Primary malignant reticuloendothelial disease involving the vagina, cervix, and corpus uteri. Obstet Gynecol 1974;44:735-48.

3. Delgado G, Smith JP, Luis D, Gallagher S. Reticulum-cell sarcoma of the cervix. Am J Obstet Gynecol 1976;126:691-4.

4. Harris NL, Scully RE. Malignant lymphoma and granulocytic sarcoma of the uterus and vagina: a clinicopathologic analysis of 27 cases. Cancer 1984;53:2530-45.

5. Iliya FA, Muggia FM, O'Leary JA, King TM. Gynecologic manifestations of reticulum cell sarcoma. Obstet Gynecol 1968;31:266-9.

6. Johnson CE, Soule EH. Malignant lymphoma as a gynecologic problem: report of five cases including one primary lymphosarcoma of the cervix uteri. Obstet Gynecol 1957;9: 149-57.

7. Komaki R, Cox JD, Hansen RM, Gunn WG, Greenberg M. Malignant lymphoma of the uterine cervix. Cancer 1984;54: 1699-704.

8. Lathrop JC. Malignant pelvic lymphomas. Obstet Gynecol 1967;30:137-45.

9. Liang R, Chiu E, Loke SL. Non-Hodgkin's lymphomas involving the female genital tract. Hematol Oncol 1990;8:295-9.

10. Makarewicz R, Kuzminska A. Non-Hodgkin's lymphoma of the uterine cervix: a report of three patients. Clin Oncol 1995;7:198-9.

11. Maryniak RK, Nasierowska-Guttmejer A. Primary malignant lymphoma of the uterine cervix: a clinicopathological evaluation of 3 cases. Eur J Gynecol Oncol 1993;14:402-5.

12. Monterroso V, Jaffe ES, Merino MJ, Medeiros LJ. Malignant lymphomas involving the ovary: a clinicopathologic analysis of 39 cases. Am J Surg Pathol 1993;17:154-70.

13. Muntz HG, Ferry JA, Flynn D, Fuller AF Jr, Tarraza HM. Stage $\mathrm{I}_{\mathrm{E}}$ primary malignant lymphomas of the uterine cervix. Cancer 1991;68:2023-32.

14. Osborne BM, Robboy SJ. Lymphomas or leukemia presenting as ovarian tumors: an analysis of 42 cases. Cancer 1983; 52:1933-43.

15. Stroh EL, Besa PC, Cox JD, Fuller LM, Cabanillas FF. Treatment of patients with lymphomas of the uterus or cervix with combination chemotherapy and radiation therapy. Cancer 1995;75:2392-9.

16. van de Rijn M, Kamel OW, Chang PP, Lee A, Warnke RA, Salhany KE. Primary low-grade endometrial B-cell lymphoma. Am J Surg Pathol 1997;21:187-94.

17. Freeman C, Berg JW, Cutler SJ. Occurrence and prognosis of extranodal lymphomas. Cancer 1972;29:252-60.

18. Lucia SP, Mills H, Lowenhaupt E, Hunt ML. Visceral involvement in primary neoplastic diseases of the reticuloendothelial system. Cancer 1952;5:1193-200.

19. Rosenberg SA, Diamond HD, Jaslowitz B, Craver LF. Lymphosarcoma: a review of 1269 cases. Med 1961;40:31-84.

20. Barcos M, Lane W, Gomez GA, Han T, Freeman A, Preisler H, 
et al. An autopsy study of 1206 acute and chronic leukemias (1958 to 1982). Cancer 1987;60:827-37.

21. Pelstring RJ, Essell JH, Kurtin PJ, Cohen AR, Banks PM. Diversity of organ site involvement among malignant lymphomas of mucosa-associated tissues. Am J Clin Pathol 1991;96:738-45.

22. Young RH, Harris NL, Scully RE. Lymphoma-like lesions of the lower female genital tract: a report of 16 cases. Int J Gynecol Pathol 1985;4:289-99.

23. Elenitoba-Johnson K, Hodges GF, King TC, Wu CD, Medeiros LJ. Extramedullary myeloid cell tumors arising in the setting of chronic myelomonocytic leukemia: a report of two cases. Arch Pathol Lab Med 1996;120:62-7.

24. Roth M, Medeiros LJ, Elenitoba-Johnson K, Kuchnio M, Jaffe ES, Stetler-Stevenson M. Extramedullary myeloid cell tumors: an immunohistochemical study of 29 cases using routinely fixed and processed paraffin-embedded tissue sections. Arch Pathol Lab Med 1995;119:790-8.
25. Lieberman PH, Jones CR, Steinman RM, Erlandson RA, Smith J, Gee T, et al. Langerhans cell (eosinophilic) granulomatosis: a clinicopathologic study encompassing 50 years. Am J Surg Pathol 1996;20:519-52.

26. Silverberg SG, Major FJ, Blessing JA, Fetter B, Askin FB, Liao $\mathrm{S}-\mathrm{Y}$, et al. Carcinosarcoma (malignant mixed mesodermal tumor) of the uterus: a Gynecologic Oncology Group pathologic study of 203 cases. Int J Gynecol Pathol 1990;9: $1-19$.

27. Clement PB, Scully RE. Endometrial stromal sarcomas of the uterus with extensive endometrioid glandular differentiation: a report of three cases that caused problems in differential diagnosis. Int J Gynecol Pathol 1992;11:163-73.

28. Adams V, Hany MA, Schmid M, Hassam S, Briner J, Niggli FK. Detection of $\mathrm{t}(11 ; 22)(\mathrm{q} 24 ; \mathrm{q} 12)$ translocation breakpoint in paraffin-embedded tissue of the Ewing's sarcoma family by nested reverse transcription-polymerase chain reaction. Diagn Mol Pathol 1996;5:107-13. 